\title{
Detection of Hepatitis Virus B And C in Archival Autopsy Specimens of Liver Cirrhosis
}

\author{
Yutaka Tsutsumi ${ }^{1 *}$, Kazuya Shiogama ${ }^{2}$, Hidemi Teramoto ${ }^{3}$, Shinichi Aishima ${ }^{4}$, Yoshinao Oda ${ }^{5}$, Riuko \\ Ohashi $^{6}$, Yoichi Ajioka ${ }^{7}$ and Makoto Naito ${ }^{8}$
}

${ }^{1}$ Pathos Tsutsumi, Nagoya, Aichi, Japan

${ }^{2}$ Division of Morphology and Cell Function, Faculty of Medical Technology, Fujita Health University School of Health Sciences, Toyoake, Aichi, Japan

${ }^{3}$ Department of Internal Medicine, Kojin Hospital, Nagoya, Aichi, Japan

${ }^{4}$ Department of Pathology \& Microbiology, Faculty of Medicine, Saga University, Saga, Japan

${ }^{5}$ Department of Anatomic Pathology, Pathological Sciences, Graduate School of Medical Sciences, Kyushu University, Fukuoka, Japan

${ }^{6}$ Histopathology Core Facility, Niigata University Faculty of Medicine, Niigata, Japan

${ }^{7}$ Division of Molecular and Diagnostic Pathology, Niigata University Graduate School of Medical and Dental Sciences, Niigata, Japan

${ }^{8}$ Department of Pathology, Niigata Medical Center, Niigata, Japan

*Corresponding author: Yutaka Tsutsumi, Pathos Tsutsumi, Nagoya, Aichi, Japan

\begin{tabular}{|c|c|}
\hline ARTICLE INFO & ABSTRACT \\
\hline Received: 凷 October 26, 2019 & \multirow{4}{*}{$\begin{array}{l}\text { The present study is aimed at clarifying the times when Hepatitis Virus B (HBV) } \\
\text { and Hepatitis Virus C (HCV) existed in Japan by analyzing archival autopsy specimens, } \\
\text { based on the epidemiological and historical point of view. Two series included: a) Ten } \\
\text { samples of liver cirrhosis autopsied during } 1907 \text { through } 1930 \text { and long fixed in forma- } \\
\text { lin at Kyushu University, Fukuoka, and b) Twenty-two paraffin blocks of cirrhotic liver } \\
\text { autopsied during } 1940 \text { through } 1957 \text { at Niigata University, Niigata. HBs antigen was im- } \\
\text { munostained using paraffin sections. HCV and its genotypes were identified by nested } \\
\text { reverse transcription-polymerase chain reaction using total ribonucleic acid extracted } \\
\text { from long-fixed tissue (Kyushu) or paraffin sections (Niigata). HBV was detected in eight } \\
\text { (80\%) of the Kyushu series, and in ten (45\%) in the Niigata series. HCV genome was de- } \\
\text { tected in two lesions in the respective series, and three belonged to genotype } 1 \text { b and one } \\
\text { to } 2 \text { b. HBV was co-infected in three of four HCV-positive lesions. One lesion in the Niigata } \\
\text { series with HCV genotype 1b without HBV co-infection showed fulminant transforma- } \\
\text { tion in cirrhotic liver. HBV infection was shown as early in 1907, and the oldest lesion } \\
\text { with HCV infection was recorded in } 1909 \text {. }\end{array}$} \\
\hline Published: 慧 November 04, 2019 & \\
\hline $\begin{array}{l}\text { tation: Yutaka Tsutsumi, Kazuya Shiog- } \\
\text { na, Hidemi Teramoto, Shinichi Aishima, } \\
\text { shinao Oda, Riuko Ohashi, Yoichi Ajioka,- } \\
\text { akoto Naito. Detection of Hepatitis Virus } \\
\text { And C in Archival Autopsy Specimens of } \\
\text { ver Cirrhosis. Biomed J Sci \& Tech Res } \\
\text { (3)-2019. BJSTR. MS.ID.003757. }\end{array}$ & \\
\hline & \\
\hline
\end{tabular}

\section{Introduction}

Archival pathology specimens long-conserved in pathology divisions are of historical value [1-4]. In some institutions, formalin-fixed tissues are preserved for a long period of time. In the present article, we tried to detect hepatitis $\mathrm{B}$ and $\mathrm{C}$ viruses in archival autopsy specimens, in order to know the times when hepatitis viruses existed in Japan, based on the epidemiological and historical point of view. The archival specimens were provided from Kyushu
University and Niigata University. Fixed human autopsy specimens are open to the public in Kyushu University Museum, Fukuoka, and 10 liver tissues of advanced liver cirrhosis autopsied in the period from 1907 to 1930 were sampled after a long fixation period. In addition, a total of 22 paraffin blocks of liver lesions (chronic active hepatitis and liver cirrhosis) autopsied in the period from 1940 to 1957 and kept in the Department of Pathology, Niigata University 
Faculty of Medicine, Niigata, were chosen. Hepatitis B Virus (HBV) was demonstrated by immunostaining for HBs antigen, while Hepatitis C Virus (HCV) was detected by nested Reverse Transcription-Polymerase Chain Reaction (RT-PCR) using total Ribonucleic Acid (RNA) extracted from fixed tissues or paraffin sections. The present report gives the direct evidence for hepatitis virus detection in archival specimens: Infection of HBV and HCV was proven even in 110-year-old formalin-fixed liver samples.

\section{Materials and Methods}

\section{Target Archival Samples}

A total of ten specimens of advanced liver cirrhosis displayed in Kyushu University Museum, Fukuoka, were sampled from long- fixed tissues. The autopsy was done in the period from 1907 to 1930 (the fixation periods reached 86-109 years). The specimens were chosen by gross appearance of cirrhosis, so that paraffin sections prepared from all the ten lesions microscopically showed liver cirrhosis of common type (Table 1). Another series included twentytwo paraffin blocks of liver specimens autopsied in the period from 1940 to 1957 and kept at room temperature in the Department of Pathology, Niigata University Faculty of Medicine, Niigata, including chronic active hepatitis and liver cirrhosis (Table 2). The specimens were chosen by three pathologists, RO, YA and MN, according to the autopsy diagnosis on the autopsy note. Hematoxylin and Eosin (HE) and Azan stains were performed to confirm histological features.

Table 1: Archival liver specimens in Kyushu University $(n=10)$.

\begin{tabular}{|c|c|c|c|c|}
\hline Number & Year & Age/Sex & Histology & HCV genome \\
\hline K1 & 1907 & $59 \mathrm{M}$ & LC + HCC & + \\
\hline K2 & 1909 & $30 \mathrm{M}$ & LC with mild inflammation & + LC+HCC, bile stasis \\
\hline K3 & 1912 & $47 \mathrm{M}$ & LC with mild inflammation \\
\hline K4 & 1914 & $43 \mathrm{M}$ & LC with fatty change & + \\
\hline K5 & 1914 & $50 \mathrm{M}$ & LC with active inflammation & + \\
\hline K6 & 1914 & $37 \mathrm{~F}$ & LC+HCC, bile ductular proliferation & + \\
\hline K7 & 1914 & $37 \mathrm{M}$ & LC with mild inflammation \\
\hline K8 & 1915 & $40 \mathrm{M}$ & LC with mild inflammation, fatty change & + \\
\hline K9 & 1916 & $31 \mathrm{M}$ & $57 \mathrm{M}$ & + \\
\hline K10 & 1930 & + & + \\
\hline
\end{tabular}

LC: liver cirrhosis, HCC: hepatocellular carcinoma.

Table 2: Archival liver specimens in Niigata University $(n=22)$.

\begin{tabular}{|c|c|c|c|c|c|}
\hline Number & Year & Age/Sex & Histology & HBs-Ag & HCV genome \\
\hline N1 & 1940 & $36 \mathrm{~F}$ & LC with mild inflammation & - & \\
\hline N2 & 1942 & $18 \mathrm{M}$ & $\mathrm{LC}+\mathrm{HCC}$ & + & \\
\hline N3 & 1944 & $65 \mathrm{M}$ & CAH with miliary tuberculosis & - & \\
\hline N4 & 1947 & $36 \mathrm{M}$ & LC with metastatic adenocarcinoma & + & \\
\hline N5 & 1947 & $26 \mathrm{M}$ & $\mathrm{CAH}$ & - & \\
\hline N6 & 1947 & $24 \mathrm{M}$ & LC with active bile ductular proliferation & + & \\
\hline N7 & 1949 & $60 \mathrm{M}$ & $\mathrm{LC}+\mathrm{HCC}$ & + & \\
\hline N8 & 1950 & $39 \mathrm{~F}$ & $\mathrm{CAH}$ with congestive necrosis & + & \\
\hline N9 & 1952 & $48 \mathrm{~F}$ & LC with fatty change & + & \\
\hline N10 & 1953 & $24 \mathrm{M}$ & LC with bile ductular proliferation & - & \\
\hline N11 & 1953 & $51 \mathrm{~F}$ & LC & - & \\
\hline N12 & 1954 & $45 \mathrm{~F}$ & LC & - & \\
\hline N13 & 1955 & $? \mathrm{M}$ & $\mathrm{LC}+\mathrm{HCC}$ & - & \\
\hline N14 & 1955 & $64 \mathrm{M}$ & LC & + & \\
\hline N15 & 1956 & $44 \mathrm{~F}$ & LC with fatty change & + & \\
\hline N16 & 1956 & $65 \mathrm{~F}$ & LC with fulminant change & - & $+(1 b)$ \\
\hline N17 & 1956 & $21 \mathrm{M}$ & LC with bile ductular proliferation & - & \\
\hline N18 & 1956 & $21 \mathrm{M}$ & LC with bile ductular proliferation & + & $+(2 b)$ \\
\hline N19 & 1956 & $37 \mathrm{M}$ & $\mathrm{LC}+\mathrm{HCC}$ & - & \\
\hline $\mathrm{N} 20$ & 1956 & $51 \mathrm{M}$ & LC with hemosiderosis & - & \\
\hline $\mathrm{N} 21$ & 1956 & $59 \mathrm{M}$ & LC with fatty change & + & \\
\hline N22 & 1957 & $14 \mathrm{~F}$ & LC & - & \\
\hline
\end{tabular}

LC: liver cirrhosis, HCC: hepatocellular carcinoma, CAH: chronic active hepatitis. 


\section{HBV Detection}

HBV infection was demonstrated by immunostaining for HBs antigen on paraffin-embedded sections. A mouse monoclonal antibody HB024 was available from Nippon Biotest Laboratories, Asaka, Saitama, and the antibody diluted at 1:500 was applied to immunostaining after heat-induced epitope retrieval in $1 \mathrm{mM}$ ethylenediamine tetraacetic acid, pH 8. Horseradish peroxidaselabelled amino acid polymers (Simple Stain-Max, Nichirei, Tokyo) were employed as the secondary reagent. Diaminobenzidine color reaction and nuclear counterstaining with Mayer's hematoxylin followed. The specificity of immunostaining was confirmed both by using known positive and negative control liver specimens and by comparing with immunostaining with a polyclonal anti-HBs antibody (Agilent Technologies, Hachioji, Japan).

\section{HCV Detection and HCV Genotyping}

HCV infection was identified by nested RT-PCR in crude total RNA extracted from fixed tissues (the Kyushu University series) or paraffin sections (the Niigata University series). The core region on the HCV genome was targeted for RT-PCR amplification. In the Kyushu University series, total RNA was extracted from a small piece of fixed cirrhotic tissue by using a Recover All Total Nucleic Acid Isolation kit (Applied Biosystems, Austin, TX). For the Niigata University series, five slices of $5 \mu \mathrm{m}$ thickness were prepared from formalin-fixed and paraffin-embedded liver tissue blocks on a microtome. A new sterile blade was used for each block to avoid contamination among the samples. Total RNA was extracted from dewaxed sections by using ReliaPrep FFPE Total RNA Miniprep System (Promega, Madison, WI). The protocol for RNA extraction from paraffin sections consisted of the following six steps [5]: microtome sectioning of paraffin blocks, deparaffinization, proteinase $\mathrm{K}$ digestion, RNA isolation, DNase incubation and RNA purification. RNA samples were stored at $-80^{\circ} \mathrm{C}$ until use.

RT-PCR was carried out by applying $1 \mu$ l of extracted RNA (reaction mixture volume, $10 \mu \mathrm{l}$ ) to the one-step RT-PCR kit (Qiagen, Valencia, CA). The universal primer pairs at a concentration of 200 nM included No.256 (5'-CGCGCGACTAGGAAGACTTC-3') and No.186 (5'-ATGTACCCCATGAGGTCGGCC-3') [6]. The thermal profile for the reaction indicated reverse transcription at $50^{\circ} \mathrm{C}$ for $30 \mathrm{~min}$ and initial denaturation at $95^{\circ} \mathrm{C}$ for $15 \mathrm{~min}$, followed by 40 cycles of denaturation at $95^{\circ} \mathrm{C}$ for $1 \mathrm{~min}$, annealing at $54^{\circ} \mathrm{C}$ for $1 \mathrm{~min}$, and elongation at $72^{\circ} \mathrm{C}$ for $1 \mathrm{~min}$. The final elongation step was done at $72^{\circ} \mathrm{C}$ for $10 \mathrm{~min}$.

The second amplification step was carried out, by employing $1 \mu \mathrm{l}$ of 1:1,000 diluted first PCR product, at $95^{\circ} \mathrm{C}$ for $5 \mathrm{~min}$, then 40 cycles of denaturation at $95{ }^{\circ} \mathrm{C}$ for $1 \mathrm{~min}$, annealing at $54^{\circ} \mathrm{C}$ for $1 \mathrm{~min}$, elongation at $72^{\circ} \mathrm{C}$ for $1 \mathrm{~min}$, and final elongation at $72^{\circ} \mathrm{C}$ for $10 \mathrm{~min}$. The nested reactions were performed using a combination of $200 \mathrm{nM}$ universal sense primer No. 104 (5'-AGGAAGACTTCCGAGCGGTC-3') and $200 \mathrm{nM}$ genotype specific antisense primer No.132 (5'-TGCCTTGGGGATAGGCTGAC-3') for type 1a, No.133 (5'-GAGCCATCCTGCCCACCCCA-3') for type 1b,
No134 (5'-CCAAGAGGGACGGGAACCTC-3') for type 2a, No135 (5'-ACCCTCGTTTCCGTACAGAG-3') for type $2 \mathrm{~b}$, and No.339 (5'-GCTGAGCCCAGGACCGGTCT-3') for type 3a [7], together with the HotStar Taq Plus Master Mix kit (Qiagen). The HCV genotype primer kit was available from Institute of Immunology Co., Tokyo. The amplified products were analysed by electrophoresis using $3 \%$ agarose gel and ethidium bromide. For confirming the efficiency of RNA extraction from paraffin sections, RT-PCR amplification of Glyceraldehyde 3-Phosphate Dehydrogenase (GAPDH), a representative house-keeping marker, was performed by using a human housekeeping gene primer set available from TaKaRa Bio Inc. (Kusatsu, Shiga, Japan) to yield 138 bp products.

The target of nested RT-PCR-mediated genotyping of HCV, using HCV-positive human sera genotypes 1a (49 bp), 1b (144 bp), 2a (174 bp), 2b (123 bp) and 3a (88 bp), is schematically illustrated in (Figure 1). Total RNA samples extracted from HCV-positive sera collected at Kojin Hospital, Nagoya, were utilised as positive controls.

\section{Results}

\section{Patients' Summary}

Cases K1-K10 were autopsied at Kyushu University in 1907 through 1930. The male to female ratio was nine-to-one, and the age ranged from 30 to 59 years (mean 43.1, median 41.5). All the livers were cirrhotic, and three lesions were associated with Hepatocellular Carcinoma (HCC). Brief comments on histologic features are described in Table 1.

The Niigata cases (N1-N22) autopsied in 1940 through 1957 showed liver cirrhosis $(n=19)$ and chronic active hepatitis $(n=3)$. HCC was associated in four cirrhotic lesions. The male to female ratio was fourteen-to-eight, and the age ranged from 14 to 65 years (mean 40.4, median 39). The age of case N13 was unknown. Brief comments on histological features are described in Table 2.

\section{Status of Hepatitis Virus Infection}

Among ten cirrhotic lesions of the Kyushu University series, HBs antigen was immunohistochemically detected in eight (80\%). HCV genome was detected in two liver lesions (cases K2 and K4), and both belonged to the genotype $1 \mathrm{~b}$ (Table 1 and Figure 1). Of note is that HBV infection was demonstrated in both of the HCVpositive lesions, indicating co-infection. The microscopic features of case K2 are illustrated in (Figure 2a \& 2b). HBV infection was shown as early in 1907, and the oldest lesion with HCV infection was recorded in 1909.

Among twenty-two lesions in the Niigata University series, HBs antigen was demonstrated in ten (45\%), and two lesions autopsied in 1956 were positive for HCV genome (Table 2 and Figure 1). One lesion with active bile ductular proliferation (case N18) showed coinfection of HBV and HCV, genotype 2b. Microscopic features of case N18 are displayed in Figure 2c \& 2d. Another lesion (case N16) with fulminant transformation in the cirrhotic liver exhibited infection of HCV genotype $1 \mathrm{~b}$ without HBV co-infection. 


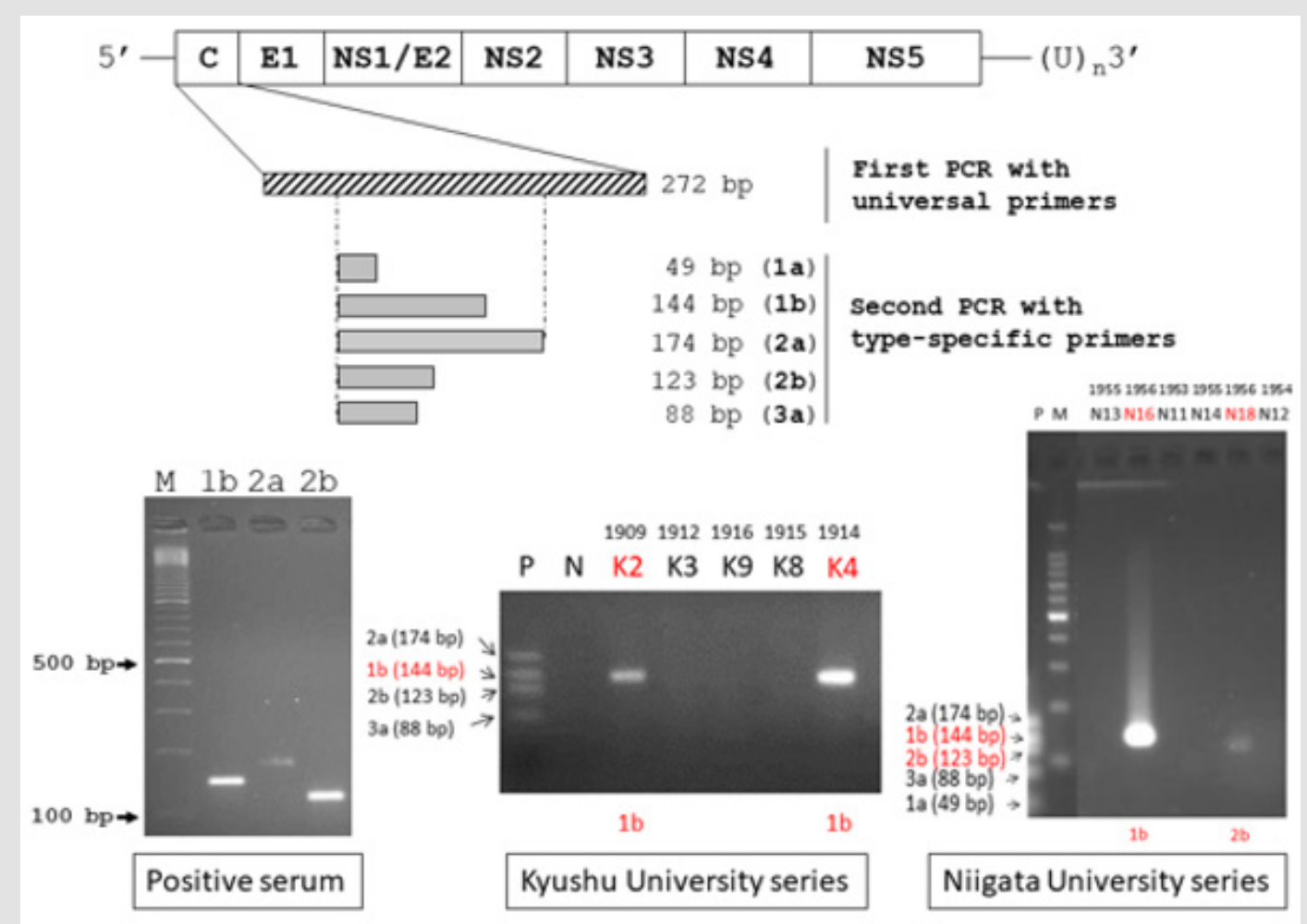

Figure 1: Schematic illustration of the genome organization of HCV and nested RT-PCR-mediated genotyping of HCV. The $\mathrm{HCV}$ genome structure and strategy of HCV genotyping are shown in the upper part (C: core region for nucleocapsid, E1-2: envelop glycoprotein regions, NS1-5: non-structural protein regions 1-5). HCV-genotypes $1 \mathrm{~b}$ (144 bp), 2a (174 bp) and 2b (123 bp) in human sera are visualized on the agarose gel (bottom left). HCV genotyping in the Kyushu University series (bottom center) and the Niigata University series (bottom right) are also illustrated. HCV genotype $1 \mathrm{~b}$ was detected in three lesions (K2, K4 and N16), while one lesion (N18) contained genotype 2b. M: molecular size markers, P: positive controls, HCV genotypes 2a (174 bp), 1b (144 bp), $2 b$ (123 bp), 3a (88 bp) and 1a (49 bp), N: negative control.

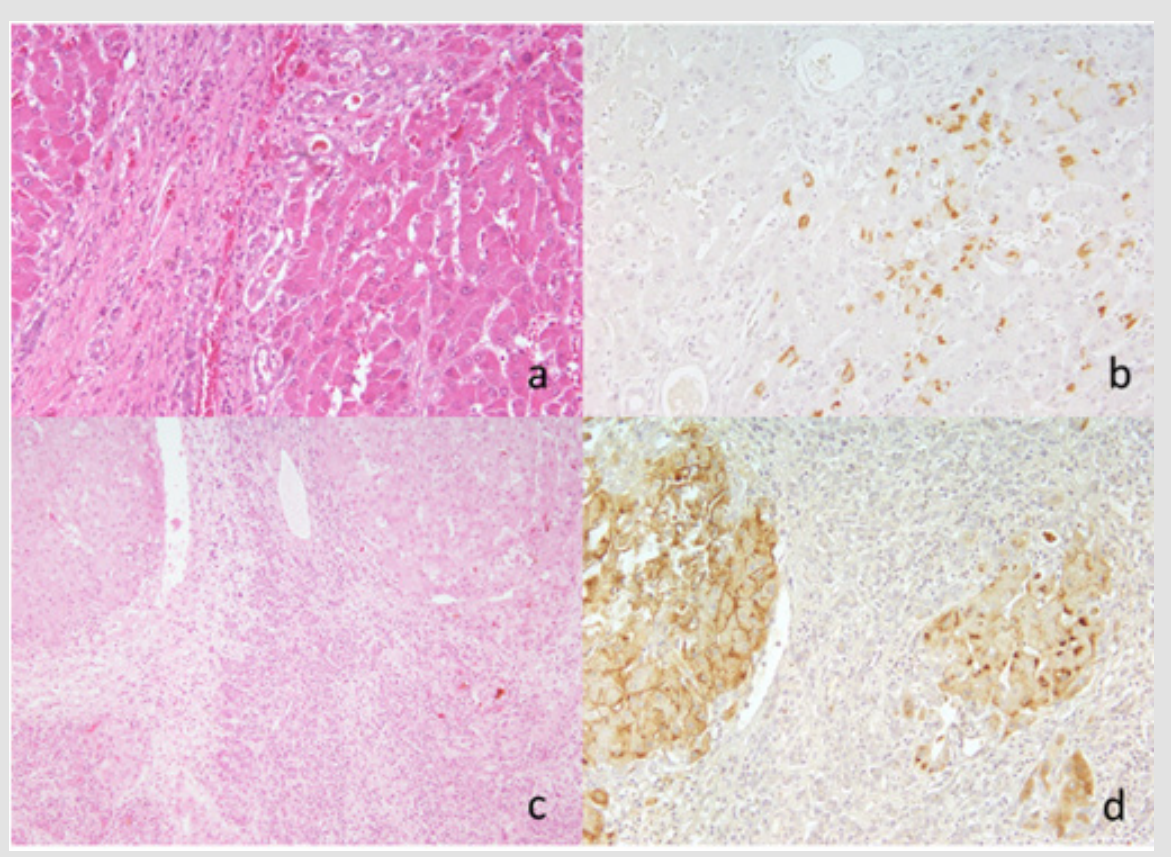

Figure 2: Cirrhotic microscopic appearance and HBs immunostaining in case K2 (a and b: HCV genotype 1b-positive) in the Kyushu University series and case N18 (c and d: HCV genotype 2b-positive) in the Niigata series. a and c: HE, b and d: immunostaining for HBs antigen using a monoclonal antibody HB024. HBV infection is observed in the cytoplasm (b) or on the plasma membrane and in the cytoplasm (d) of hepatocytes in archival paraffin sections of liver cirrhosis. Bile ductular proliferation is noted in the panel c. 
By RT-PCR analysis, GAPDH signals were consistently demonstrated in all the RNA samples.

\section{Discussion}

We demonstrated the usefulness and value of archival liver specimens for detecting HBV and HCV. Of surprising note is that HBs antigen and HCV genome tolerated prolonged storage of paraffin sections, as well as long fixation in formalin. Reportedly, HBs antigen and HBV genome were detectable after 60 days storage of blood at room temperature [8]. It is nearly impossible for us to obtain archival serum or blood samples without keeping in freezers. The pathology tissues can thus be incarnated as historical invaluable assets. HBV was detected in the cirrhotic liver specimens as early in 1907 and HCV in 1909.

HBV infection was observed as frequently as $80 \%$ in the Kyushu University series $(n=10)$ autopsied in 1907 through 1930. In the Niigata University series autopsied in 1940 through 1957, HBs antigen was demonstrated in ten (45\%) of twenty-two lesions. HCV genome was detected in a total of four lesions, and three $(75 \%)$ of them showed co-infection with HBV. The genotype belonged to $1 \mathrm{~b}$ in three lesions and $2 \mathrm{~b}$ in one. One lesion with HCV $1 \mathrm{~b}$ infection without HBV co-infection revealed fulminant transformation in the cirrhotic liver (marked parenchymal loss with bile ductular proliferation).

As shown in our archival specimens, genotype 1 is known to be most common among HCV prevailing in the world [9]. Co-infection of both HBV and HCV, common in highly endemic areas and among high-risk individuals such as injection drug users and hemodialysis patients, accelerates progression to cirrhosis and HCC $[10,11]$. Infrequently, cases of fulminant hepatitis $\mathrm{C}$ have been recorded so far $[12,13]$. Pathobiology of viral hepatitis in the era before 1957 significantly differed from the present status.

In 1963, Blumberg et al. discovered Australian (Au) antigen or HBs antigen from the blood of Australian aborigine [14]. HCV was identified by Choo et al. much later in 1989 [15]. At present, natural history of infection of HBV and HCV has been detailed [16,17]. Analysis using archival pathology samples has been reported infrequently. HBV and HCV genomes were successfully amplified in paraffin-embedded liver samples in 1952 through 1960 [18], and HBV and HCV in liver cancer of atomic bomb survivors in Hiroshima and Nagasaki in the period from 1958 to 1987 were demonstrated [19]. Puiu recently identified HBV genome in Italian mummy 450 years earlier [20]. The present study may record the world-oldest detection of hepatitis $\mathrm{C}$ virus, we believe.

In Japan, the spread of hepatitis viruses can be linked to two distinct events [21]: The widespread treatment of schistosomiasis with intravenous injection of antimony sodium tartrate since 1923 [22], and the intravenous abuse of methamphetamine during and after the Second World War, often repeatedly sharing needles and syringes. Another important cause should include vaccination for tuberculosis and small-pox for school children and regional inhabitants without disposing needles until the 1970's [23]. The Meiji Government of Japan under Emperor Meiji established the public health agenda for small-pox vaccination as early as in 1874, and the inoculation became common in Japan at the end of $19^{\text {th }}$ century [24].

In these periods of time, tuberculosis and Helicobacter pyloriinduced peptic ulcer prevailed, and after the Second World War, the pulmonary and gastric lesions were surgically removed often with the need of blood transfusion. Many blood donors belonged to paid professionals, and the "Yellow Blood" was often contaminated with hepatitis viruses. Half of the blood recipients received the Yellow Blood, and HCV genotype $1 \mathrm{~b}$, probably introduced during the 1880 's, started to spread in the 1920's and the 1930's [25].

In conclusion, this should be the first proof for the earliest occurrence of HCV infection in 1909 by analyzing archival autopsied liver specimens. We also demonstrated by nested RT-PCR using type-specific primers that HCV genotypes $1 \mathrm{~b}$ already existed more than 100 years ago in Japan. HBV was detected in the paraffinembedded liver specimen autopsied in 1907. It is noteworthy that co-infection of HBV and HCV was common since it was seen in three of four HCV-positive cases. In 1956, HCV genotype 1b provoked fulminant transformation in a young patient. Archival pathology specimens are of epidemiological and historical importance and value for detecting hepatitis virus infection.

\section{References}

1. Willis R (1947) The past, present and future of the museum of pathology. Ann Roy Col Surg Engl 1: 55-57.

2. Tsutsumi Y (2003) Demonstration of Epstein-Barr virus genome in archival paraffin sections of Hodgkin's lymphoma autopsied by Dr. Thomas Hodgkin nearly 170 years ago. Acta Histochem Cytochem 36: 511-514.

3. The Royal College of Pathologists and the Institute of Biomedical Science! (2015) The Retention and Storage of Pathological Records and Specimens ( $5^{\text {th }}$ Edition).

4. Cooke RA (2017) History of the historical specimens: A Cooke's tour to find the remaining pathology specimens collected during WW1 by the pathologists in the various combatant countries.

5. Ribeiro-Silva A, Zhang H, Jeffrey SS (2007) RNA extraction from tenyear-old formalin-fixed paraffin-embedded breast cancer samples: A comparison of column purification and magnetic bead-based technologies. Brit Med Council Mol Biol 8: 118.

6. Okamoto H, Sugiyama Y, Okada S, Kurai K, Akahane Y, et al. (1992) Typing hepatitis $C$ virus by polymerase chain reaction with type-specific primers: Application to clinical surveys and tracing infectious sources. J Gen Virol 73: 673-679.

7. Okamoto H, Tokita H, Sakamoto M, Horikita M, Kojima M, et al. (1993) Characterization of the genomic sequence of type $\mathrm{V}$ (or $3 \mathrm{a}$ ) hepatitis $\mathrm{C}$ virus isolates and PCR primers for specific detection. J Gen Virol 74: 2385-2390.

8. Hara J, Tanaka Y, Kaneko H, Itoh Y, Ikegaya H (2018) Detection of hepatitis B virus DNA and HBs Ag from postmortem blood and bloodstains. Arch Virol 163(3): 633-637. 
9. Messina JP, Humphreys I, Flaxman A, Brown A, Cooke GS, et al. (2015) Global distribution and prevalence of hepatitis C virus genotypes. Hepatology 61(1): 77-87.

10. Liu Z, Hou J (2006) Hepatitis B virus (HBV) and hepatitis C virus (HCV) dual infection. Int J Med Sci 3(2): 57-62.

11. Chen F, Zhang J, Wen B, Luo S, Lin Y, et al. (2016) HBV/HCV dual infection impacts viral load, antibody response, and cytokine expression differently from HBV or HCV single infection. Sci Rep 6, Article number: 39409.

12. Farci P, Alter HJ, Shimoda A, Govindarajan S, Cheung LC, et al. (1996) Hepatitis C virus-associated fulminant hepatic failure. New Engl J Med 335(9): 631-634

13. Younis BB, Arshad R, Khurhsid S, Masood J, Nazir F, et al. (2015) Fulminant Hepatic Failure (FHF) due to acute hepatitis C. Pak J Med Sci 31(4): 1009-1011.

14. Blumberg BS, Gerstley BSJ, Hungerford DA, London WT, Sutnick A] (1967) A serum antigen (Australia antigen) in Down's syndrome, leukemia and hepatitis. Ann Int Med 66(5): 924-931.

15. Choo Q-L, Kuo G, Weiner AJ, Overby LR, Bradley DW, Houghton M (1989) Isolation of a cDNA clone derived from a blood-borne non-A, non-B viral hepatitis genome. Science 244(4902): 359-362.

16. Pan CQ Zhang JX (2005) Natural history and clinical consequences of hepatitis B virus infection. Int J Med Sci 2(1): 36-40.

17. Chen SL, Morgan TR (2006) The natural history of hepatitis C virus (HCV) infection. Int J Med Sci 3(2): 47-52.

\section{ISSN: 2574-1241}

DOI: 10.26717/BJSTR.2019.22.003757

Yutaka Tsutsumi. Biomed J Sci \& Tech Res

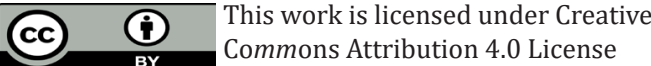

Submission Link: https://biomedres.us/submit-manuscript.php
18. Mizuno T, Nagamura H, Iwamoto KS, Ito T, Fukuhara F, et al. (1998) RNA from decades-old archival tissue blocks for retrospective studies. Diagn Mol Pathol 7(4): 202-208.

19. Fukuhara T, Sharp GB, Mizuno T, Itakura H, Yamamoto M, et al. (2001) Liver cancer in atomic-bomb survivors: Histological characteristics and relationships to radiation and hepatitis B and C viruses. J Rad Res 42(2): 117-130.

20. Puiu T (2018) Medieval mummy shows people have been infected with hepatitis B at least for centuries. ZME Sci Jan 5.

21. Tanaka Y, Hanada K, Mizokami M, Yeo AE, Shih JW, et al. (2002) A comparison of the molecular clock of hepatitis $C$ virus in the United States and Japan predicts that hepatocellular carcinoma incidence in the United States will increase over the next two decades. Proc Nat Acad Sci USA 99(24): 15584-15589.

22. Iida F, Iida R, Kamijo H, Takaso K, Miyazaki Y, et al. (1999) Chronic Japanese schistosomiasis and hepatocellular carcinoma: Ten years of follow-up in Yamanashi Prefecture, Japan. Bul World Health Org 77: 573-581.

23. Higuchi M, Tanaka E, Kiyosawa K (2002) Epidemiology and clinical aspects on hepatitis C. Jpn J Infect Dis 55(3): 69-77.

24. Jannetta A (2009) Jennerian vaccination and the creation of a national public health agenda in Japan, 1850-1900. Bul Hist Med 83(1): 125-140.

25. Mizokami M, Tanaka Y, Miyakawa Y (2006) Spread times of hepatitis $C$ virus estimated by the molecular clock differ among Japan, the United States and Egypt in reflection of their distinct socioeconomic backgrounds. Intervirology 49(1-2): 28-36.

$\begin{array}{ll}\text { BIOMEDICAL } & \text { Assets of Publishing with us } \\ \text { RESEARCHES } & \text { - Global archiving of articles } \\ & \text { - Immediate, unrestricted online access } \\ \end{array}$

